\title{
CRITERIA THAT INFLUENCE THE CHOICE OF VOCATION - THE USE OF HOLLAND'S METHOD TO OPTIMIZE THE PROCESS OF SELECTING STUDENTS FOR AVIATION STUDIES
}

\author{
A. Puskunigis \\ Vilnius College of Higher Education. E-mail:aurimasp@yahoo.com \\ Received 2006-03-28, accepted 2006-12-11
}

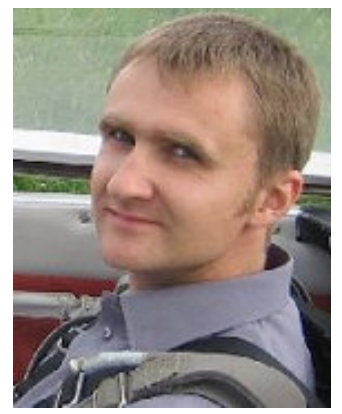

\begin{abstract}
Aurimas PUSKUNIGIS
Date and place of birth: 19761029 Birstonas, Lithuania

Education: 2002-2004 - Vilnius Pedagogical University, Master of Psychology; 1998-2002 - Vilnius Pedagogical University, Bachelor of Philosophy.

Employment experience and skills: More than one-year employment experience in personnel selection and consulting (personnel search, selection, motivation, evaluation, personality characteristics preparation, microclimate research and related work. $200509-200606$ lecturer at Vilnius Gediminas Technical University. Since 200609 - lecturer at at Vilnius College of Higher Education.
\end{abstract}

\begin{abstract}
The work contains the use of Holland's method to optimize the process of picking students to study aviation. In the first stage of research, scientific literature was analyzed. Factors influencing the choice of profession were discussed and methods of research were chosen. In the second stage of research, a survey using Holland's free choice questionnaire and a questionnaire (in shortened form) prepared by Prof. D. Beresnevičienė and related to favorite subjects, courses and electives, value orientations, and self-assessment were conducted in the $10^{\text {th }}$ and $12^{\text {th }}$ forms of four secondary schools in Vilnius. Two hundred pupils were questioned. In the third stage of research, statistical analysis of the data gathered was done.
\end{abstract}

Keywords: Holland's method, personality types, vocational singleness.

\section{Introduction}

The choice of profession is the choice of your future occupation. This can be an occupation (or several) that gives sense and satisfaction for a period of life. But only a proper selection can be using for society, one's country, and, especially, the person himself.

In his work "Polity", one of the most famous philosophers, Plato (427-347 b.c.), declares that the main prerequisite for a healthy state is a well-organized repartition of society, namely to several certain socialvocational levels [6].

According to Plato, every individual is born already labeled with the tag that corresponds to his future work, life and social class. It is therefore necessary to closely observe and examine every candidate: everyone, at different ages should take their chances in a number of different jobs and occupations to find out where one is best. The chosen ones (for a certain work) are the ones who did a certain job best in all periods of age.

\section{Vocational self-determination is influenced by a number of varying criteria}

The issue of professional suitability and the factors influencing it has been a headache for hundreds, or even thousands of authors since the days of antiquity. But we can undoubtedly say that this issue will be topical under the theoretical and practical aspects. The factors influencing vocational determination constantly vary depending on economic and social circumstances, different populations.

\section{The variety of factors}

Vocational determination is influenced by a number of criteria, such as the following:

- socioeconomic [2, 5, 4];

- psychological (professional maturity; intellect and, specifically, abilities; professional interests; motivation; volubility orientation; mettle and temper; self-esteem) [2, 3];

- other criteria, like one's sex, etc. [5, 3]. 
So we can definitely say that vocational singleness and the criteria influencing it is different in different age and sex groups.

\section{Holland's vocational determination theory}

We should take a closer look at J. Holland's vocational determination theory (1973), which is widely used nowadays [1]. This scientist offered to sort individuals by behavior type, that reflects one's main interests, likes, powers, suitable for specifically. The result of many factors is a type that the individual is most similar to. The main and the most common factors are the following: influence of family and other important people, educational and social background, earlier work experience, cultural influence, and many more things determining values and attitude.

Holland focused on six main personality types:

- The Realistic (R) type. Individuals of this type choose realistic professions, e.g. mechanical engineering, production planning, building inspection, work protection, etc. They have mechanical skills, are well built, and prefer working outdoors with mechanical tools, gadgets, and other gear. They prefer working with tools rather than working with people. Rtype personalities are described as tractable, straightforward, warm, humble, practical, tough, and economical.

- The Investigative (I) type. This type of person chooses scientific professions such as biochemistry, anthropologist economist, and management analysis. They are talented mathematicians and scientists. They like working and solving problems on their own. Itype people prefer working with ideas rather than people or things. They are commonly described as analytical, infusive, methodical, rational, careful, independent, through, quiet, complex, clever, smart, and humble.

- The Artistic (A) type. Such people are commonly architects, writers, technical editors, composers, and interior designers. They have exclusive artistic skills like creating original, unique pieces, and have an impressive, wild imagination. A-type people, like E-type people, prefer working with ideas rather than with things. Described as: straight-out, original, imaginative, intuitive, emotional, independent, idealistic, uncommon and "standing above the crowd".

- The Social (S) type. These people are best suited for the work of teachers, psychologists, speech therapists, personnel managers, etc. They have social skills, are interested in people's relationships, and help solve other's problems. They prefer working with people rather than with things. The S-type is described as helpful, responsible, idealistic, social, tactical, friendly, warm, charitable, patient, and understanding.
- The Enterprising (E) type. This type of person mostly chooses the profession of representative, financial manager, realty agent, trade manager, broker, lawyer, etc.

They have leadership skills, are interested in economics and politics and seek to be important. They prefer working with people and ideas rather than with things. The E-type is described as adventure loving, strenuous, optimistic, extraverted, popular, communicative, and selfconfident.

- The Conventional (C) type. Such people are commonly accountants, bookkeepers, budget analysts, programmers. They have officer skills and are often talented at mathematics. They prefer working indoors with texts and numbers or organizing things. The C-type is described as tractable, practical, acquiescent, economic, tidy, consistent and honest.

\section{Holland's method}

- Holland's methodic questionnaire consists of three parts: work, capabilities, and professions. Questions are answered as "yes" or "no". When the test is completed, the positive answers are added, and according to the sum, one of three dominative personality types is determined. According to Holland's code, a list of appropriate professions is given.

- Holland's test links the interests of an individual with over a thousand professions, so this test is useful for picking students for aviation studies.

\section{Use of Holland's method in picking students for aviation studies}

According to the dominative-type combinations, we focus on the following specialties: helicopter pilot (RIS), aircraft navigator (RIE), air traffic operator (RIE), aircraft engine mechanic (REI), flight head-instructor (RES and SRE), flight manager (RES and ESI), freight pilot (IRE), aviation engineer (ISR), flight instructor (SRE), etc.

\section{The research of vocational singleness}

Research in four secondary schools (students in the grades $10^{\text {th }}$ and $12^{\text {th }}$ ) was conducted using Holland's method described earlier. Another questionnaire (by Prof. D. Beresnevičienè) with questions about value orientations, self-assessment, etc. was also given.

\section{The studies}

A total of 200 randomly chosen students a hundred $10^{\text {th }}$ graders and a hundred $12^{\text {th }}$ graders from four secondary schools in Vilnius were questioned. 


\section{Hypotheses}

1. Boys and girls have different types of vocational singleness.

2. There are differences among types of vocational singleness and value orientations.

3. There are differences among types of vocational singleness and self-assessment.

\section{Data processing}

Mathematical-statistical data analysis was made using a computer programme called SPSS for Windows. The Chi-square, Student's, and Anova criteria's were invoked.
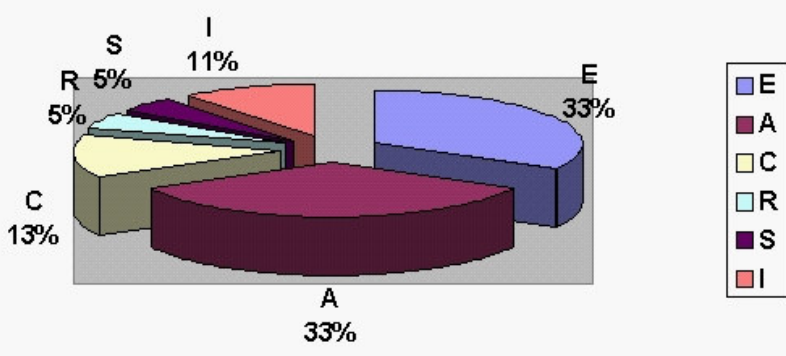

Fig 1. Repartitioning, according to type

With the Chi-squared $(\chi 2)$ criteria invoked, statistically important differences were discovered among dominating professions and sexes $(\mathrm{p}=0.000)$ :

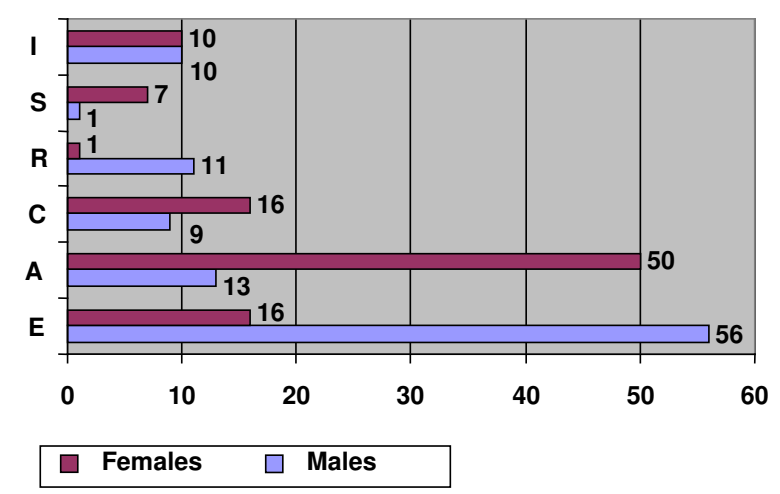

Fig 2. Sex and vocational singleness

\section{Values and vocational singleness}

With the Anova criteria invoked, statistically important differences between types of professions were found:

- possibility to grow as a personality $(\mathrm{p}=0.027)$,

- $\operatorname{good}$ pay $(\mathrm{p}=0.041)$,

- ability to create $(\mathrm{p}=0.000)$,

- ability to study and constantly improve oneself as a specialist $(\mathrm{p}=0,007)$.
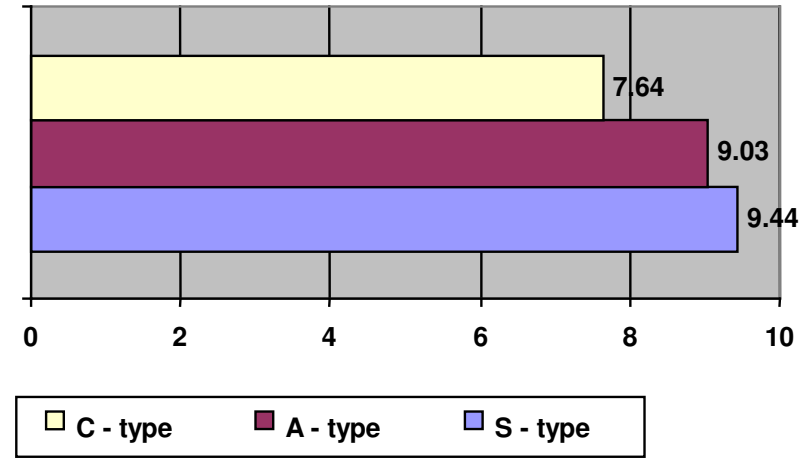

Fig 3. Possibility to grow as a personality

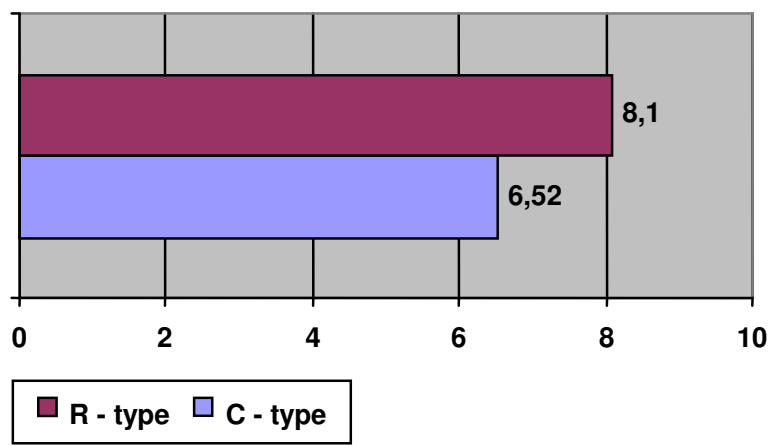

Fig 4. The ability to study and constantly improve yourself as a specialist

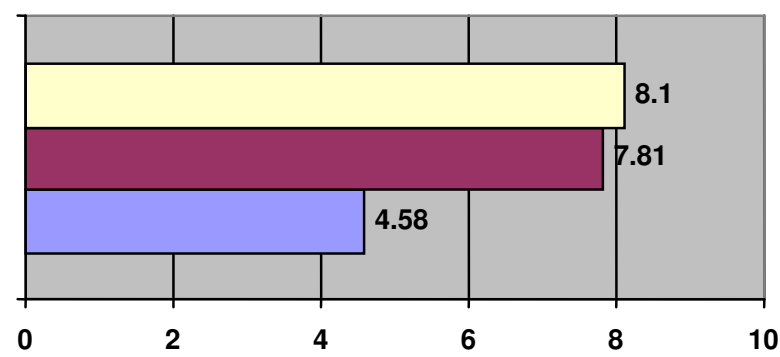

$\square$ R-type $\square$ A-type $\square$ C-type

Fig 5. The ability to create

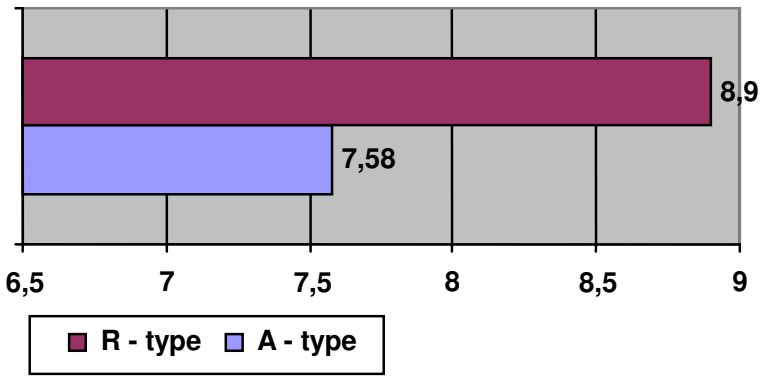

Fig 6. Good pay

Involving the Anova criteria, statistically important differences between types of professions and "strong" self-evaluation were discovered $(\mathrm{p}=0.003)$. 


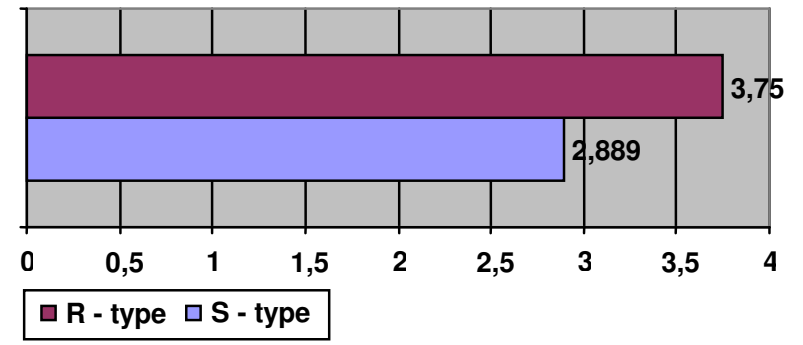

Fig 7. Self-determination

Some statistically important differences were also found among $10^{\text {th }}$ graders. "Strong" and "friendly" evaluation of features $(p=0.008$ and $p=0.022)$ :

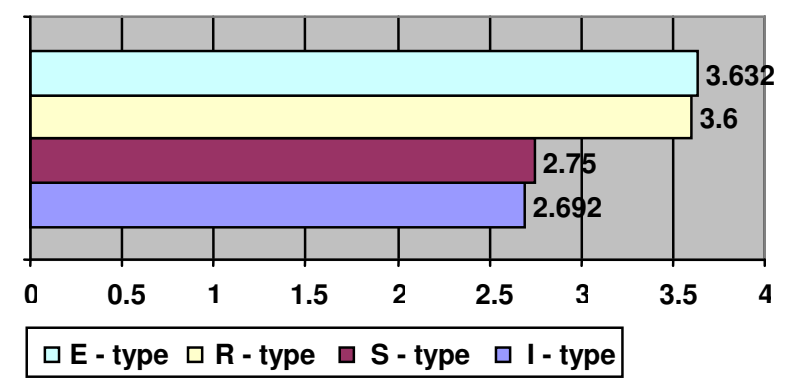

Fig 8. Strong

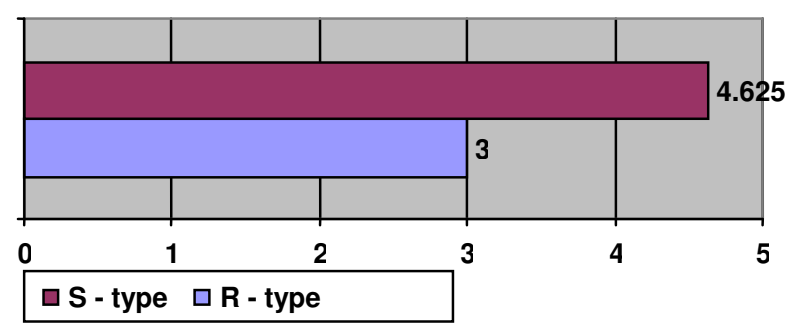

Fig 9. Friendly

A statistically important difference among female students was discovered. The feature "hard-working" $(\mathrm{p}=0.005)$ :

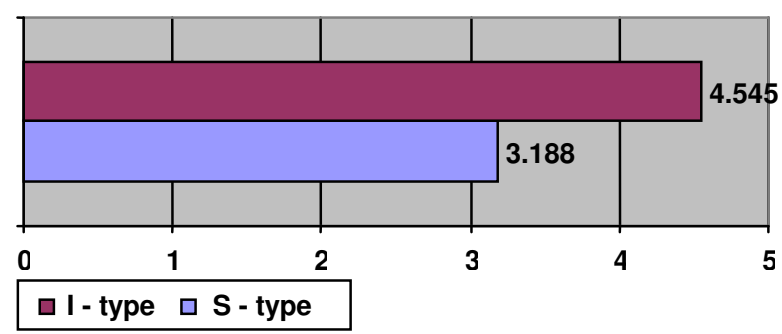

Fig 10. Hard-working

\section{Conclusions}

Statistically important differences were found while analyzing the differences of boys and girls vocational singleness according determined dominant types: boys are predominantly the enterprising (E) and girls are predominantly the artistic (A) type. We can predicate that hypothesis I (different types of vocational singleness dominate among boys and girls) was proved.

A lot of statistically important differences were found while analyzing the differences among the values and types of vocational singleness of pupils. We can predicate that hypothesis II (there are differences among types of vocational singleness and value orientations) was also proved.

Statistically significant differences were found while analyzing differences among pupils self-assessment and types of vocational singleness, so we can predicate that hypothesis III (there are differences among types of vocational singleness and self assessment) was proved too.

The factors that influence vocational selfdetermination constantly vary, and depend on social and economic circumstances, different to different populations.

Holland's test links a person's abilities with more than 1000 professions (including pilot, flight-control operator, aviation engineer, etc), so this test is useful for selecting suitable students for studying aviation.

The screening of students for aviation studies can be optimized using Holland's method, evaluating statistically important differences between profession and personality types and using the help of external sources such as questionnaires or interviews.

\section{References}

1. HOLLAND, JI. Making vocational choices: A theory of careers. New York, 1973.

2. JOVAIŠA, L. Asmenybè ir profesija. Kaunas, 1981.

3. KREGŽDE், S. Profesinio kryptingumo formavimosi psichologiniai pagrindai. Kaunas, 1988.

4. MATULIONIS, A.; MIKŠYS, A. Jaunimo socialinè - profesinè orientacija. Vilnius, 1992.

5. PETRAUSKAITE், R. Psichopedagogika profesijos pasirinkimui. Vilnius, 1996.

6. PLATONAS. Valstybė. Vilnius, 1981. 